\title{
FUZZY LOGIC SYSTEM FOR FREQUENCY STABILITY ANALYSIS OF WIND FARM INTEGRATED POWER SYSTEMS
}

\author{
Wang Jiang, Jiping Lu
}

Original scientific paper

This paper introduces a fuzzy logic system to analyse the frequency response of wind farms composed of variable speed wind turbine generators (WTGs). WTGs can provide frequency support by using their energy reserves. However, the frequency response of an individual WTG is different from that of other WTGs because of their respective actual wind speeds. The frequency response model based on the direct-current load flow is investigated and used to amend the membership functions of the logic system. When a network disturbance occurs, the fuzzy logic system can determine the frequency response of the wind farm according to real-time input variables. The simulation results indicate that the designed system is effective and can contribute to frequency stability analysis.

Keywords: frequency stability; fuzzy logic; wind power integration

\section{Sustav fuzzy logike u analizi frekvencijske stabilnosti integriranih energetskih sustava vjetroelektrana}

Izvorni znanstveni članak

U radu se uvodi sustav fuzzy logike u analizi frekvencijskog odziva vjetroelektrana sastavljenih od generatora s turbinama na vjetar promjenljive brzine variable speed wind turbine generators (WTGs). WTGs mogu pružiti frekvencijsku podršku koristeći svoje zalihe energije. Međutim, frekvencijski odziv pojedinačnog WTG razlikuje se od odziva drugih WTGs zbog njihovih različitih brzina vjetra. Istražuje se i koristi model frekvencijskog odziva utemeljen na protoku opterećenja istosmjerne struje kako bi se poboljšale funkcije članice sustava logike. Kad se pojave smetnje na mreži, sustav fuzzy logike može odrediti frekvencijski odziv vjetroelektrane prema ulaznim varijablama realnog vremena. Rezultati simulacije pokazuju da je projektirani sustav učinkovit i može doprinijeti analizi frekvencijske stabilnosti.

Ključne riječi: frekvencijska stabilnost; fuzzy logika; integracija energije vjetra

\section{Introduction}

With the development of wind energy technology, the proportion of wind-generated power in power systems has increased significantly. The United Kingdom uses $10 \%$ of the total electricity demand, which is up to $10 \mathrm{GW}$ and was supplied by renewable forms of energy generation in 2010. Wind power may contribute up to $60 \%$ of the renewable energy source. In many countries, the average wind power penetration is $20 \%$ or higher [1, 2]. The growing use of wind power is causing concern regarding system frequency stability caused by inertia reduction. When dealing with variable speed wind turbine generators (WTGs) with rotor speeds that are decoupled from the system frequency, the inertia contribution of a WTG is significantly smaller than that of conventional generators. The power system faces more frequency stability challenges with the rising penetration of wind power [3].

Variable-speed WTGs are becoming more popular than the fixed-speed WTGs. Extensive research has been conducted on frequency control, particularly for the doubly-fed induction generator (DFIG), which is reported in several articles referred to in references. The frequency response varies with the different types of generators. Conventional generators can provide frequency responses by releasing rotor kinetic energy. By contrast, the DFIG converter decouples the mechanical and electrical frequencies. The DFIG has no inertia response during system frequency variations. Therefore, the DFIG penetration can reduce system inertia and affect frequency responses if it replaces synchronous generation [3, 4]. A comparative analysis of the frequency responses of the DFIG and the fixed-speed WTG is illustrated in [5]. The DFIG can add an additional frequency control loop to participate in system frequency control. The deloading control enables wind turbines to reserve the available power for frequency responses instead of operating at the maximum power point tracking [6]. The active power can be changed by altering the pitch angle. The droop control method enables variable-speed WTGs to simulate the similar frequency droop characteristics of conventional generators. WTGs can produce an active power output change by decreasing the rotor speed. However, this process restricts the speed because the turbine might stall if the rotational speed exceeds the limit [7].

Previous research indicates that the growing wind power integrated capacity influences system frequency characteristics. However, most studies focus on the detailed methods to participate in frequency control for wind generation. At present, there is not a suitable standard for evaluating the frequency stability of wind power integrated systems. The frequency stability of a wind power integrated system is a complicated problem. Random and highly fluctuating wind speed conditions exist, and sudden network disturbances in the system should be considered. The frequency response of a largescale wind farm (WF) consists of the individual frequency responses of each WTG according to its own situation. The main contribution of our paper is to establish a fuzzy logic system for analysing frequency stability of wind farm integrated power systems, which is based on the direct-current load-flow based frequency response model. In order to calculate the frequency response characteristic quickly, the DFR model is used to simplify the system model in system modelling section. The fuzzy logic system can calculate the frequency response of the WF according to its real-time wind speed and operation state. In Section 2, the modelling of the various system components is described. The equivalent inertia time constant of the wind farm is presented in Section 3. The 
fuzzy logic system is developed in Section 4. In Section 5, simulation results are discussed. Section 6 concludes the paper.

\section{System modelling}

When the reactive power reserves are abundant and the excitation system has a strong regularability, the influence of the voltage on the frequency dynamic is small. To investigate the space-time distribution characteristic of the frequency reflected on the network topology, the dynamic changes of the reactive powervoltage can be ignored. The direct-current load-flow based frequency response model (DFR) is introduced to analyse the active-frequency dynamic characteristic [8].

Assuming that the terminal voltage of the generator is constant, both the excitation system and power system stabilizer (PSS) will not be considered in modelling. The influence of the damping windings and salient pole effect can be eliminated.

\subsection{Doubly-fed induction generator model}

The doubly-fed induction generator model (DFIG) is one of the most representative variable-speed WTGs, and can operate at different wind speeds or extract the maximum available wind power. DFIGs have power electronic interfaces and can achieve the decoupled control of the active and reactive powers. DFIGs have no response to the frequency excursion because the rotational speed is decoupled from the grid frequency [9].
The DFIG wind turbine can adjust the rotational speed deviation by using the pitch angle to control the device. Ensuring that the adjusting speed of the output power regulation tracks the trend of wind speed is impractical because of the large moment of inertia of the wind turbine. This study considers only the pitch angle rotational speed control model, which is

$\frac{\mathrm{d} \beta}{\mathrm{d} t}=\frac{1}{k_{s}}\left(k_{p} \Delta \omega_{m}-\beta\right)$

where $k_{s}$ is the inertia time constant of the adjustment device, $k_{p}$ is the gain factor, and $\Delta \omega_{m}$ is the speed error of the wind turbine.

The mathematical relation of the output power extraction from the wind can be expressed as [10]

$P=\frac{1}{2} \rho A V_{m}^{3} C_{P}(\lambda, \beta)$,

where $P$ is the mechanical power, $\rho$ is the air density, $A$ is the area swept by the blade, $V_{m}$ is the wind speed, $C_{P}$ is the power coefficient with the function of the tip speed ratio $(\lambda)$, and $\beta$ is the blade pitch angle.

A DFIG-based WTG system is used in this study. Fig. 1 presents a simplified schematic representation of the DFIG with a pitch angle controller. The DFIG can respond to frequency changes and release the kinetic energy of the rotating mass by implementing the inertial controller shown in Fig. 1 [11].

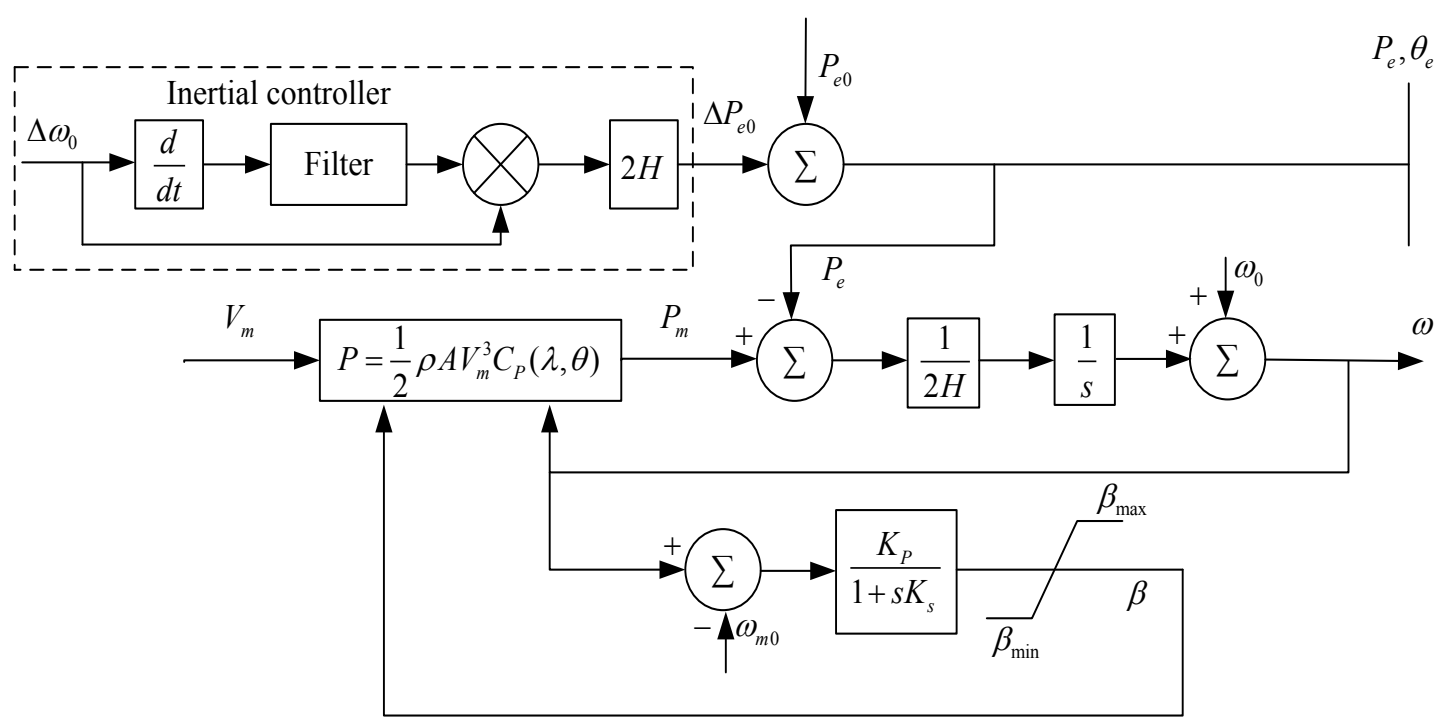

Figure 1 Simplified DFIG model

\subsection{Simplification of network model}

The DFR model can reflect the imbalanced power redistribution between the different units and the spacetime features of the frequency dynamics with the simplified network [12]. Only the active power is considered; thus, a few assumptions must be accepted. The voltage magnitude of each node is 1,0 p.u. The resistance, charging capacitor, and shunt compensation of the branches are ignored. The voltage phase angle is extremely small. The network model is simplified to a linear model

$$
P=\boldsymbol{B} \theta
$$

where $P$ and $\theta$ are the active power injection and voltage angle, respectively, of all the buses except the slack bus, and $\boldsymbol{B}$ is the network susceptance matrix.

The simplified generating units, network, and other equipment are indicated in the proposed DFR model 
shown in Fig. 2. The DFR model can be described with the different algebraic equations

$$
\left\{\begin{array}{l}
\dot{x}=f(x, y) \\
0=g(x, y)
\end{array},\right.
$$

where $x$ represents the state variables and $y$ represents the algebraic variables. The turbine governors and inertia equations can be expressed by the differential equations. The algebraic equations are used to illustrate the network and load model.

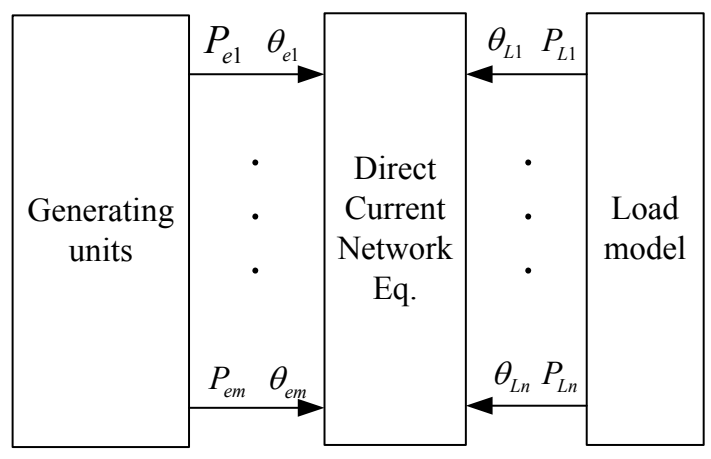

Figure 2 Schematic of DFR model

Under the condition of sharing the same system frequency, the frequency response of the multi-turbine system can be expressed as follows:

$$
\begin{aligned}
& \Delta \omega(s)=\frac{\Delta P_{m \Sigma}(s)-\Delta P_{\mathrm{e}}(s)}{2 H_{\mathrm{eq}} s+D}, \\
& \Delta P_{m \Sigma}=\sum_{i=1}^{m} \frac{S_{i}}{S_{\mathrm{sys}}} \Delta P_{m i}, \\
& H_{\mathrm{eq}}=\frac{\sum_{i=1}^{m} H_{i} S_{i}}{S_{\mathrm{sys}}}, \\
& D=\frac{\sum_{i=1}^{n} P_{L i} K_{P i}}{S_{\mathrm{sys}}},
\end{aligned}
$$

where $\Delta P_{m \Sigma}(s)$ denotes the mechanical power variations, $\Delta P_{\mathrm{e}}(s)$ is the electromagnetic power, $H_{\mathrm{eq}}$ is the equal inertia time constant of the total system, $D$ is the damping coefficient, $S_{i}$ and $S_{\text {sys }}$ are the respective base values of the unit capacity and total system, $P_{L i}$ is the rated power of the load, and $K_{P i}$ is the load coefficient.

\section{Equivalent inertia time constant of wind farm}

With the introduced supplementary control loop, the DFIG can contribute inertial responses to the system for sudden frequency disturbances. The effect of the inertial response of the WF cannot be ignored. However, the frequency response of the WF is time varying and according to the different operation conditions of each WTG. The mechanical inertia of the WTG is also different from that of a conventional synchronous generator when considering the frequency response of the WTG.
To calculate the accurate inertial response of the WF, this paper introduces the equivalent inertia time constant of wind farm as follows [13]

$$
\begin{aligned}
& H_{\mathrm{WF}}=\frac{\sum_{i=1}^{n} \frac{1}{2} J_{i} \omega_{\mathrm{nom}}^{2}}{S}, \\
& J=\frac{J_{\mathrm{tur}}}{k^{2}}+J_{\mathrm{gen}},
\end{aligned}
$$

where $S$ is the rated apparent power, $J_{i}$ is the mechanical inertia, $\omega_{\text {nom }}$ denotes the rated mechanical rotation speed, $k$ is the gearbox ratio, $J_{\text {tur }}$ is the turbine moment of inertia, and $J_{\text {gen }}$ is the generator moment of inertia. These equations can compute the equivalent inertia time constant for WTGs of the same type in real time.

\section{Fuzzy logic system}

WTGs increase the operation complexity of largescale WF integrated power systems. WTGs can affect the frequency stability because of the random and unpredictable fluctuating wind speeds. Sudden power changes at the side of the system can also lead to frequency variations. It is hard to provide a precise model to reflect the frequency response characteristic of the complicated system. According to the fluctuating and random inputs (wind speed and number of paralleloperated WTGs), fuzzy logic can adapt well and determine the frequency response of the WF.

\subsection{Input variables}

The stored kinetic energy is dependent on the wind speed level for variable-speed WTGs. Fig. 3 shows the power curve with different rotational speeds. For low wind speeds, the kinetic energy is small because of the tiny output power; for middle wind speeds, the output power and stored kinetic energy can be rationally distributed by simultaneous torque and pitch control. The output power is guaranteed when the WTG operates near the rated speed [14].

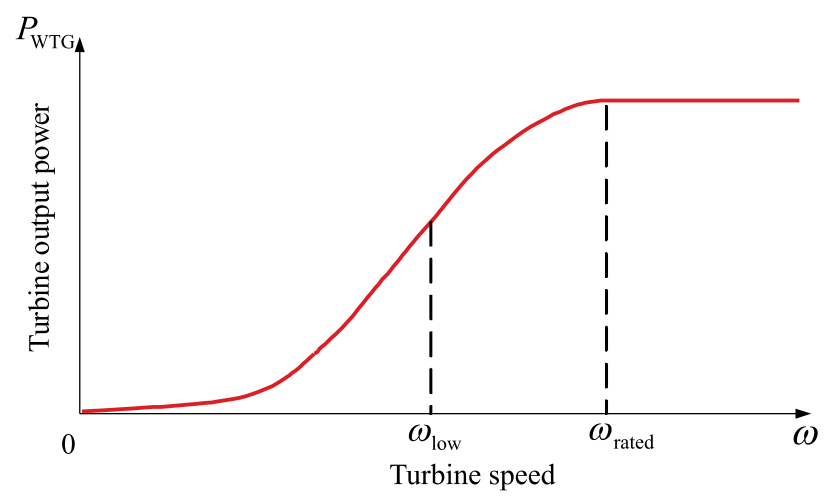

Figure 3 Output power curve of variable-speed WTG

Considering the wind speed of each WTG is certainly different at the same time, this study uses the average wind speed of WF $V_{\text {wind }}$. The wind speed was divided into three levels based on the magnitudes of cut-in and cut-out wind speed of WTG. Fig. 4 illustrates the membership 
functions (MFs) of the wind speeds, which follow a normal distribution.
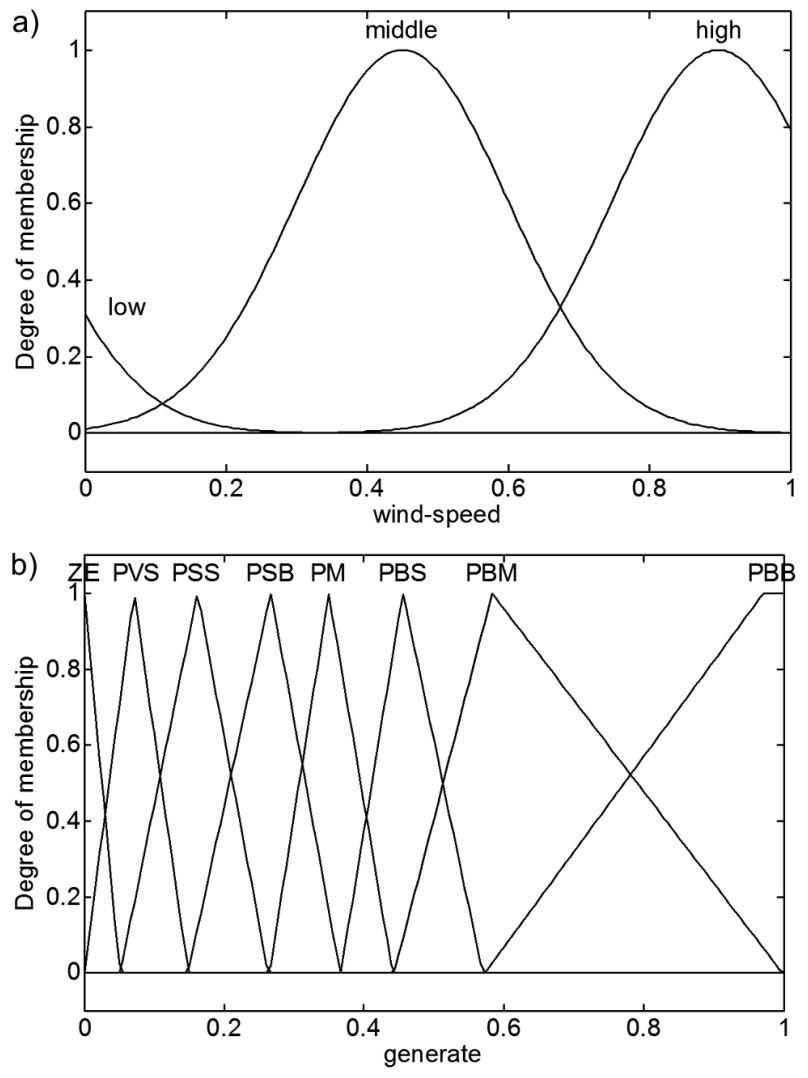

Figure 4 Membership functions of input variables. (a) Wind speed. (b) Number of WTGs

The real-time measured number of parallel-operated WTGs can avoid mismatch conditions wherein the local wind speed is either extremely large or extremely small. Furthermore, WTG failures or maintenance scheduling can also be avoided. Fig. 4 shows the MFs of the unit number. The MFs indicate a gradually increasing tendency as the number of WTGs increases.

Table 1 Fuzzy rules for all combinations of input variables

\begin{tabular}{|c|c|c|c|}
\hline$n$ & PS & PM & PB \\
\hline ZO & ZO & ZO & ZO \\
\hline PVS & PVS & PSS & PVS \\
\hline PSS & PVS & PM & PSS \\
\hline PSB & PSS & PBS & PM \\
\hline PM & PM & PBM & PBS \\
\hline PBS & PBS & PBB & PBM \\
\hline PBM & PBM & PVB & PBB \\
\hline PBB & PBB & PBB & PBB \\
\hline
\end{tabular}

\subsection{Inference}

The system employs the Mamdani type inference because it is the most widely used and proven methodology [15]. Tab. 1 presents the complete fuzzy rules for all the combinations of inputs (ZO, PVS, PSS, PS, PSB, PM, PBS, PB, PBM, and PBB refer to zero, positive very small, positive small small, positive small, positive small big, positive medium, positive big small, positive big, positive big medium, and positive big big, respectively).

\subsection{Structure of the fuzzy logic system}

Fig. 5 describes the reasoning training process of the fuzzy logic system. All of the input variables use the representation of the quantifying factor. The total frequency response caused by the corresponding power margin $\Delta P$ can be calculated by Eq. (6). The frequency response of the WF $\Delta \omega_{b}(p u)$ can be obtained by removing the response of the conventional generator from the grid side. The weights and MFs of the inputs can be further improved by error checking.

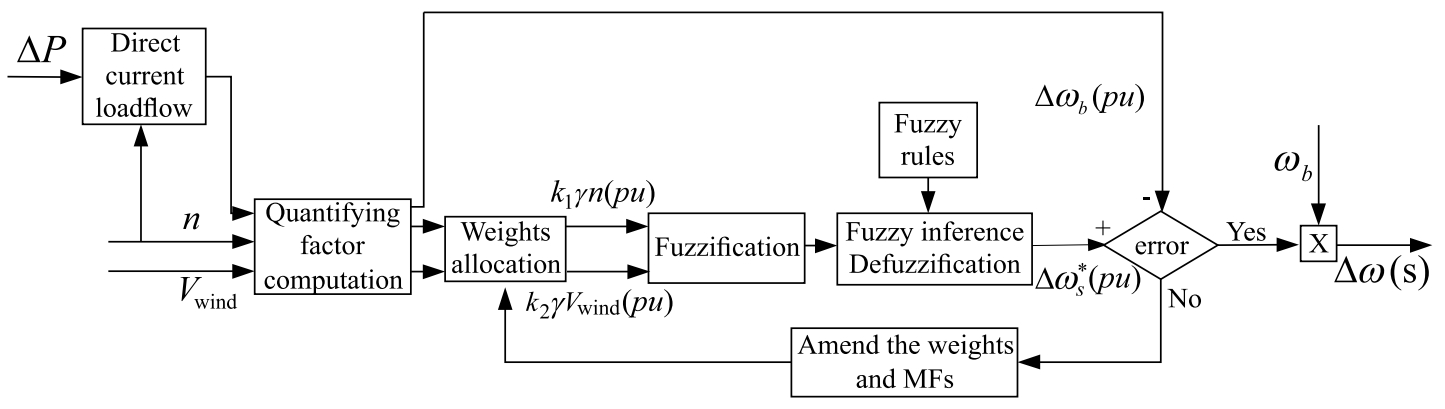

Figure 5 Structure of fuzzy logic system

\section{Test system}

In this study, the IEEE 14-bus system integrated with 30 DFIGs is considered. Each WTG is of 2 MW capacity, and the WF is connected to the IEEE 14-bus system by a $110 \mathrm{kV}$ bus $(5,686+j 23,954 \Omega)$ in node 14 . The inertia constants of the conventional units and WTG are shown in Tab. 2. The supplementary control loop of the DFIG is modelled as in [16]. The main electrical parameters for the wind turbine generator model are described in [17]. The detailed structure of network can be found in [18]. The cut-in wind speed is $3 \mathrm{~m} / \mathrm{s}$, the rated wind speed is $13,5 \mathrm{~m} / \mathrm{s}$, and the cut-out wind speed is $20 \mathrm{~m} / \mathrm{s}$. The wind farm used a three-parameter Weibull model, where $\alpha=2$, $\beta=11$, and $v_{0}=2$. All of the simulations are carried out by using DigSilent Power Factory 14.1.

Table 2 Inertia constants of generators

\begin{tabular}{|c|c|}
\hline Generator & Inertia time constant \\
\hline Gen 1(250MVA) & $10,296 \mathrm{~s}$ \\
\hline Gen 2(200MVA) & $13,08 \mathrm{~s}$ \\
\hline Gen 3(60MVA) & $13,08 \mathrm{~s}$ \\
\hline Gen 4(50MVA) & $10,12 \mathrm{~s}$ \\
\hline Gen 5(60MVA) & $10,12 \mathrm{~s}$ \\
\hline DIFG(2MVA) & $4,4 \mathrm{~s}$ \\
\hline
\end{tabular}




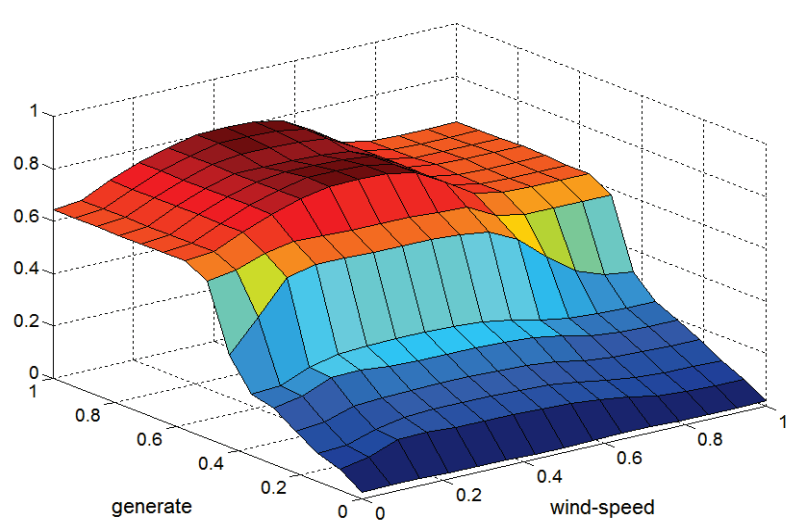

Figure 6 Generated surface for frequency response

To verify the effectiveness of the proposed system, two cases with different situations are considered in this study. When the power balance is broken, the system begins to sample the input variables every two seconds. The frequency curve was fitted according to the test results, which were compared with the simulation results, to prove correctness and applicability. Fig. 6 presents the generated surfaces for the WF frequency response, with a possible maximum power disturbance of $\Delta P_{\max }$. When the speed is low or the number of parallel-operated WTGs is small, the corresponding frequency response is also small. The peak value appears when the speed is near the rated speed and the number reaches the maximum. If wind speed is too high, the WTG will be cut off and the frequency response also decreased. The $\Delta P$ can be determined according to the practical situation. $\Delta P$ in the text system ranges from $-60 \mathrm{MW}$ to $60 \mathrm{MW}$.

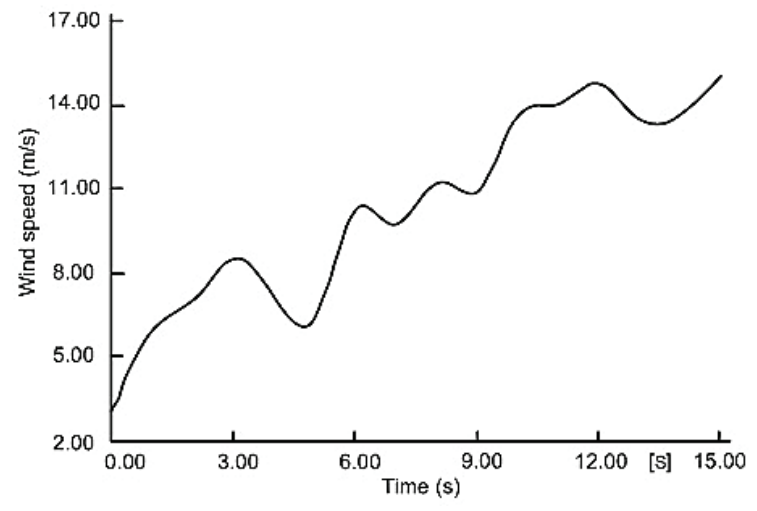

Figure 7 Wind speed of case A

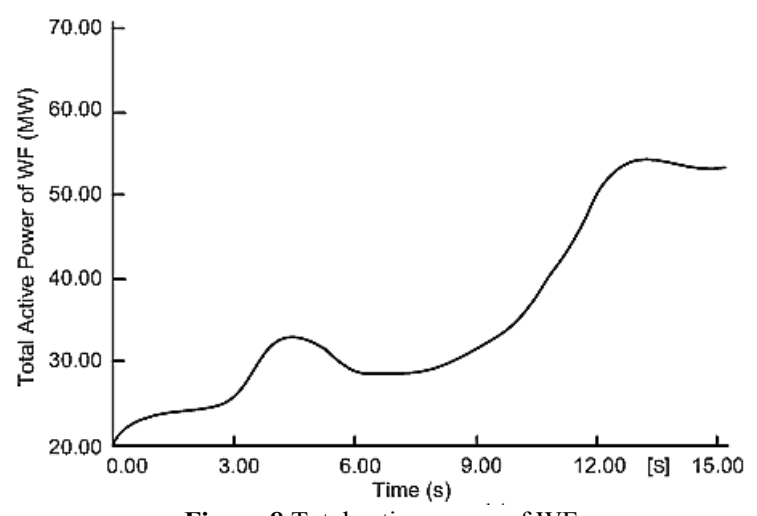

Figure 8 Total active power of WF

Case A presents a situation wherein a short circuit fault occurs when the wind speed changes from weak to strong. Fig. 7 describes the process in which the wind speed of the WF increases from $3 \mathrm{~m} / \mathrm{s}$ to $15 \mathrm{~m} / \mathrm{s}$. The total active power of the WF is shown in Fig. 8.The output is close to the rated power when the wind speed is near 13.5 $\mathrm{m} / \mathrm{s}$. The short-circuit fault occurs in node 8 at time $6,0 \mathrm{~s}$.

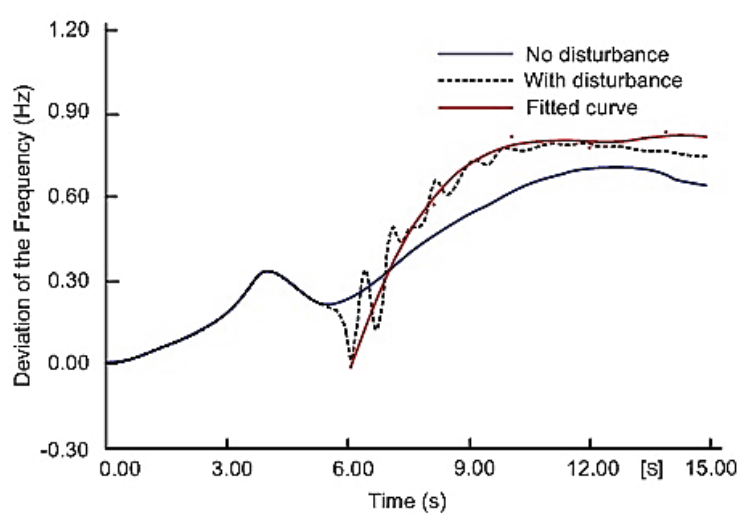

Figure 9 Frequency deviation of power system

The frequency deviation is shown in Fig. 9. During the disturbance, the frequency first decreases by $0,15 \mathrm{~Hz}$ when the WF operates in the low wind speed region. The frequency response of the WF does not change the downward tendency of the frequency. However, the active power of generator 5 is not large enough to significantly change the frequency. The output power of the WF cannot fill up the vacancies as soon as possible.

The total inertial time constant of the power system, which directly affects the rate of the frequency change, decreases by 10,12 s because Generator 5 has been cut off at $6,0 \mathrm{~s}$. With the increase of the wind velocity and the number of WTGs, the WF increases its power output and provides power support to the frequency response. The frequency gradually increases and tends to be stable. Based on the fitted curve (shown as a red line in Fig. 9), the frequency nadir is $49,88 \mathrm{~Hz}$ at $6,0 \mathrm{~s}$, which is 0,013 $\mathrm{Hz}$ smaller than the simulation results. A WF with ample wind can successfully stabilize a system frequency with power disturbance.

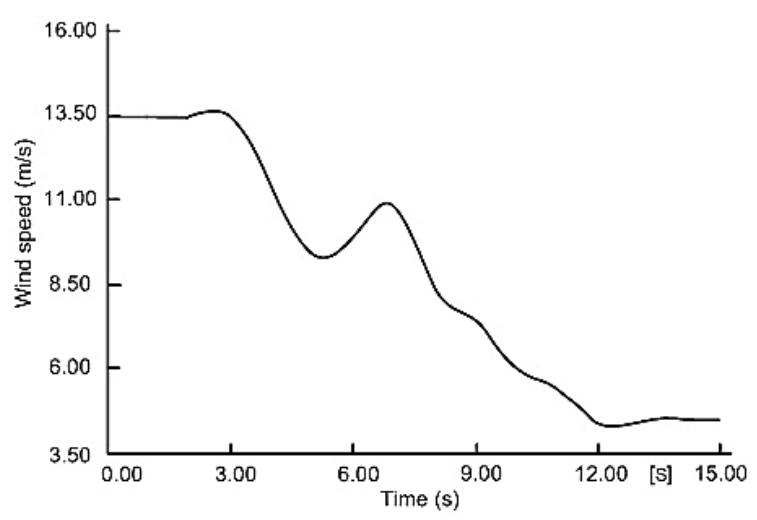

Figure 10 Wind speed of case B

Case B describes a situation wherein a sudden load change occurs when the wind speed drops from the rated speed. Fig. 10 indicates the wind speed falling to approximately $4 \mathrm{~m} / \mathrm{s}$ from the rated speed.

Fig. 11 shows a decreasing WF power, which corresponds well to the wind speed change. At 9,0 s, the load demand of node 9 suddenly increases by $50 \%$. By 
contrast, the system frequency suddenly drops, which can be attributed to the load demand mutation. The conventional generators rapidly reduce the rotor speed to provide frequency support. However, the output power of the WF still decreases because the wind speed is in a process of decline. This condition further expands the active power vacant. The WTGs have been cut off by the low wind speed, which decreases the equivalent inertial time constant $H_{\mathrm{WF}}$.

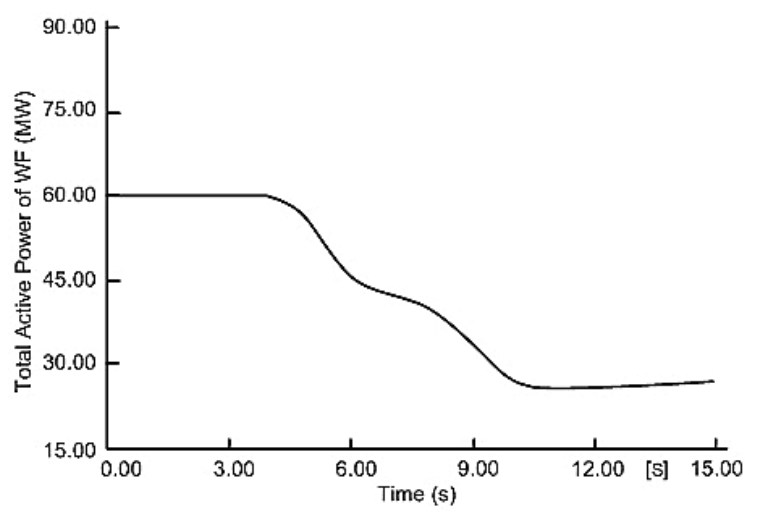

Figure 11 Total active power of WF

The rate of the frequency change is also significantly enlarged, as shown in Fig. 12. The figure also shows that the frequency nadir of the fitted model is $0,012 \mathrm{~Hz}$ less than the simulation results. This fact may be attributed to the fuzzy logic system using the DFR model, which does not consider the voltage fluctuations of real power systems. The comparison shows that the inference results are close to the simulation results with regard to frequency deviation detection.

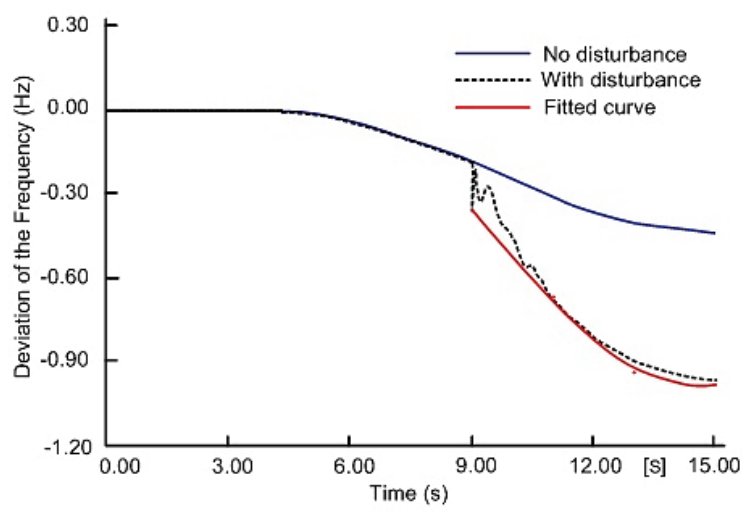

Figure 12 Frequency deviation of power system

In this situation, the integrated WF cannot provide frequency support to power systems. On the contrary, the integrated WF creates a smaller frequency nadir and poses a threat to the frequency stability of the system. An underfrequency load shedding strategy has to be considered to avoid frequency deterioration.

Two kinds of neutral network algorithms have been selected for comparison, which are momentum back propagation algorithm and conjugate back propagation algorithm. Tab. 3 shows the detailed parameters of two algorithms. The training times of momentum back propagation is 13072, which is already beyond the maximum iterations. It is limited by low convergence rate and it is easy to fall into local minima and saturation region.

\begin{tabular}{|c|c|c|c|c|}
\hline Algorithm & $\begin{array}{c}\text { Training } \\
\text { times }\end{array}$ & Parameters & $\begin{array}{c}\text { Terminal } \\
\text { goal } \\
\text { error }\end{array}$ & $\begin{array}{c}\text { Maximum } \\
\text { iterations }\end{array}$ \\
\hline $\begin{array}{c}\text { Momentum } \\
\text { back } \\
\text { propagation }\end{array}$ & 13072 & $\begin{array}{c}\text { Learning } \\
\text { coefficient } \\
=0,1 \\
\text { Momentum } \\
\text { constant }=0,9 \\
\text { Minimum } \\
\text { gradient } \\
=1 \mathrm{e}-10\end{array}$ & 0,001 & 10000 \\
\hline $\begin{array}{c}\text { Conjugate } \\
\text { back } \\
\text { propagation }\end{array}$ & 112 & $\begin{array}{c}\text { Minimum } \\
\text { gradient } \\
=1 \mathrm{e}-9\end{array}$ & 0,001 & 10000 \\
\hline
\end{tabular}

Results of Fig. 13 show the frequency deviation error of both cases. Black bars stand for the frequency dynamics results of fuzzy logic system, the white bars correspond to frequency dynamics of full-time domain simulation, and the grey bars stand for the conjugate back propagation algorithm. The convergence effect of conjugate back propagation algorithm is determined by the appropriate line search function. The network training is so dependent on the learning samples, which directly influences the error of results. The maximum error is 0,28 $\mathrm{Hz}$, which is much larger than the proposed method. The results of the conjugate back propagation algorithm are influenced by the input samples, the error can fluctuate significantly, which is unsuitable for the frequency stability analysing.

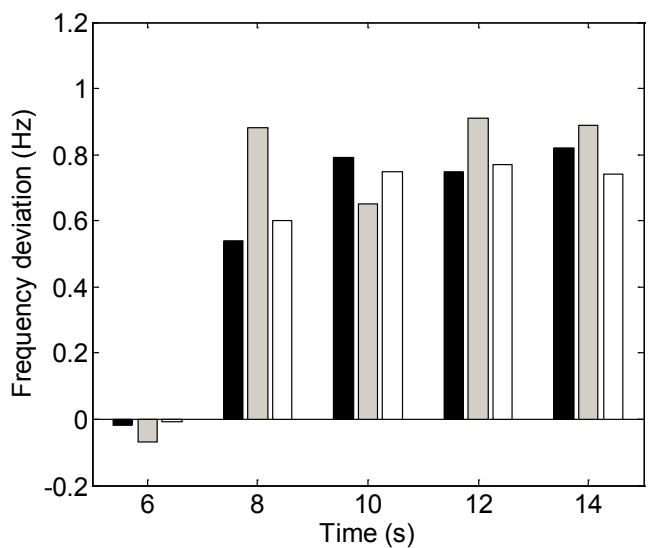

(a)

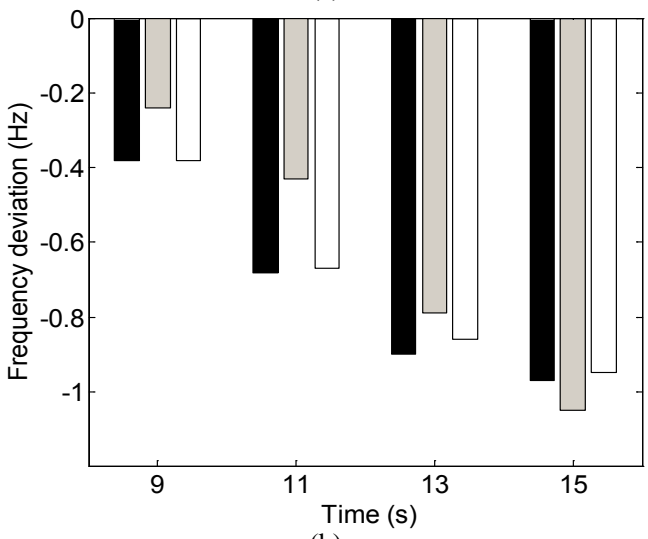

(b)

Figure 13 Frequency deviation error. (a) Case A. (b) Case B 
The frequency deviation error of fuzzy logic system is no more than $0,06 \mathrm{~Hz}$ and the root mean squares (RMS) of both cases are $5,04 \times 10^{-2} \mathrm{~Hz}$ and $2,355 \times 10^{-2} \mathrm{~Hz}$, respectively. It can be seen from Fig. 13 that the fuzzy logic system shows fine consistency with the simulation results, it is able to reflect the frequency dynamics of complicated conditions with wind power integrated. It cannot only save the calculation time but also make sure the error is in an acceptable range.

\section{Conclusion}

This paper presents a new analytical method for system frequency stability with wind power penetration. The proposed approach is based on fuzzy logic and is designed to help variable-speed DFIGs determine the frequency response value of the integrated wind farm in real time. Random, unpredictable, fluctuating wind speeds and sudden power changes in the system are considered in the fuzzy logic supervisor. Based on the premise that the dynamic changes in the reactive power-voltage are ignored, the DFR model is introduced to modify the MFs of the fuzzy logic system.

This advantage of the fuzzy logic system helps the proposed method determine the real-time frequency response of WF and the possible maximum frequency deviation during network disturbances. The fuzzy logic system enhances both the calculation amount and calculation accuracy. The simulation results indicate the accuracy of the dynamic performance using real wind speed data. The fuzzy logic system can be useful in judging the frequency stability of the wind integrated power system. The fuzzy logic system also provides data to assist network managers in formulating frequency control strategies.

\section{Acknowledgements}

Project Supported by State Key Laboratory of Power Transmission Equipment\& System Security and New Technology Autonomous Research Foundation (Chongqing University) (2007DA10512712205).

\section{References}

[1] Holdsworth, L.; Ekanayake, J.; Jenkins, N. Power system frequency response from fixed speed and doubly fed induction generator-based wind turbines. // Wind Energy. 7, 1(2004), pp. 21-35. DOI: 10.1002/we.105

[2] Lin, J.; Sun, Y. Z.; Sørensen, P. Method for assessing grid frequency deviation due to wind power fluctuation based on Time-Frequency transformation. // IEEE Trans. Sustain. Energy. 3, 1(2012), pp. 65-73. DOl: 10.1109/TSTE.2011.2162639

[3] Mullane, A.; O'Malley, M. The inertial response of induction-machine-vase wind turbines. // IEEE Trans. Power Syst. 20, 3(2005), pp. 1496-1503. DOI: 10.1109/TPWRS.2005.852081

[4] Villena-Lapaz, J.; Vigueras-Rodriguez, A.; Gomez-Lazaro, E.; Molina-Garcia, A.; Fuentes-Moreno, J. A. Evaluation of frequency response of variable speed wind farms for reducing stability problems in weak grids. // Power Electronics and Machines in Wind Applications (PEMWA) / Denver, 2012, pp. 1-5.
[5] Loukarakis, E.; Margaris, I.; Moutis, P. Frequency control support and participation methods provided by wind generation. // Electrical Power \& Energy Conference / Montreal, 2009, pp. 1-6.

[6] Yuan-zhang, S.; Zhao-sui, Z.; Guo-jie, L.; Jin, L. Review on frequency control of power systems with wind power penetration. // Power System Technology Conference (POWERCON) / Hangzhou, 2010, pp. 1-8.

[7] Conroy, J. F.; Watson, R. Frequency response capability of full converter wind turbine generators in comparison to conventional generation. // IEEE Trans. Power Syst. 23, 2(2008), pp. 649-656. DOI: 10.1109/TPWRS.2008.920197

[8] Li, Changgang; Liu, Yutian; Zhang, Hengxu. Fast Analysis of Active Power-Frequency Dynamics Considering Network Influence. // IEEE Power and Energy Society General Meeting / San Diego, 2012, pp.1-6.

[9] Lalor, G.; Mullane, A.; O'Malley, M. Frequency control and wind turbine technologies. // IEEE Trans. Power Syst. 20, 4(2005), pp. 1905-1913. DOI: 10.1109/TPWRS.2005.857393

[10] Muyeen, S. A variable speed wind turbine control strategy to meet wind farm grid code requirements. // IEEE Trans. Power Syst. 25, 1(2010), pp. 331-340. DOI: 10.1109/TPWRS.2009.2030421

[11] Holdsworth, L.; Ekanayake, J.; Jenkins, N. Power system frequency response from fixed speed and doubly fed induction generator based wind turbines. // Wind Energy, 7(2004), pp. 21-35. DOI: 10.1002/we.105

[12] Stott, B.; Jardim, J.; Alsac, O. DC Power Flow Revisited. // IEEE Transactions on Power Systems. 24, 3(2009), pp. 1290-1300. DOI: 10.1109/TPWRS.2009.2021235

[13] Kayikci, M.; Milanovic, J. V. Dynamic contribution of DFIG-based wind plants to system frequency disturbance. // IEEE Trans. Power Syst. 24, 2(2009), pp. 859-867. DOI: 10.1109/TPWRS.2009.2016062

[14] Morren, J. S.; de Haan, W. H.; Kling, W. L.; Ferreira, J. A. Wind turbine emulating inertia and supporting primary frequency control. // IEEE Trans. Power Syst. 21, 1(2006), pp. 433-434. DOI: 10.1109/TPWRS.2005.861956

[15] Soon Kiat Yee; Milanovic, J. V. Fuzzy Logic Controller for Decentralized Stabilization of Multimachine Power Systems. // IEEE Trans. on Fuzzy Systems. 16(2008), pp. 971-981. DOI: 10.1109/TFUZZ.2008.917296

[16] Vidyanandan, K. V.; Senroy, N. Primary frequency regulation by deloaded wind turbines using variable droop. // IEEE Trans. Power Syst. 28, 2(2013), pp. 837-846. DOl: 10.1109/TPWRS.2012.2208233

[17] Littler, T.; Fox, B.; Flynn, D. Measurement-based Estimation of Wind Farm Inertia. // IEEE Power Tech Conference / Petersburg, Russia, 2005, pp. 1-5. DOI: 10.1109/ptc.2005.4524432

[18] Jiang, Wang; Lu, Jiping. Frequency estimation in wind farm integrated systems using artificial neural network. // International Journal of Electrical Power and Energy $\begin{array}{llll}\text { Systems. } & \text { 62(2014), pp. } & \text { 72-79. DOl: }\end{array}$ 10.1016/j.jijepes.2014.04.027

\section{Authors' addresses}

Wang Jiang, Ph.D. student

State Key Laboratory of Power Transmission Equipment \& System Security and New Technology, College of Electrical Engineering, Chongqing University, Chongqing, China E-mail: jwop-90@163.com

\section{Jiping Lu, Professor}

State Key Laboratory of Power Transmission Equipment \& System Security and New Technology, College of Electrical Engineering, Chongqing University, Chongqing, China

E-mail: lujiping@cqu.edu 